\title{
SISTEMA DE ORIENTAÇÃO TÉCNICA AO CLIENTE DO VAREJO DE MATERIAL DE CONSTRUÇÃO'
}

\author{
TECHNICAL GUIDANCE SYSTEM TO THE BUILDING MATERIAL RETAIL \\ CUSTOMER
}

\author{
Paulo Henrique Aveniente Santos \\ Escola Politécnica da Universidade de São Paulo (USP) \\ paulo.aveniente@usp.br \\ Eduardo Toledo Santos \\ Escola Politécnica da Universidade de São Paulo (USP) \\ etoledo@usp.br
}

\begin{abstract}
Resumo
A Cadeia da Construção Civil vem sofrendo com a escassez de mão-de-obra direta e indireta qualificada, como consequência do baixo investimento direcionado a capacitação nos últimos anos. Os reflexos deste cenário, especificamente no setor de varejo de materiais de construção, vão desde vendas incorretas, incompletas, excesso ou desperdícios de materiais em obras. Diante deste fato, este trabalho foca-se em propor um Sistema de Orientação Técnica (SOT) ao cliente do varejo de material de construção que visa auxiliar os públicos relacionados em lojas acima de $300 \mathrm{~m}^{2}$. Com isto, visa mostrar a importância da informação na disseminação do conhecimento para o público relacionado, que em sua grande maioria não tem o conhecimento em soluções técnicas atuais para auxiliar suas necessidades. Em virtude desta falta de preparo, justifica-se a criação de um SOT ao cliente do varejo de material de construção. Este será baseado na criação de uma plataforma que auxiliará este público em relação as suas dúvidas para uma correta especificação. Como estudo de caso, adotou-se o tema "impermeabilização", utilizando-se um sistema de diagnóstico. Desta forma, espera-se que haja uma consequente melhoria na qualidade das vendas e um aumento no tíquete-médio das lojas.
\end{abstract}

Palavras-chave: Construção Civil. Capacitação Profissional. Competências. Sistemas de Orientação. Comunicação no Ponto de Venda.

\begin{abstract}
The Construction supply-chain has been suffering with shortages of laborers as a consequence of low investments targeted at capacity-building in recent years. The reflections of this scenario, specifically in the retail industry of construction materials, are incorrect, incomplete sales, surplus or waste of materials in sites. Given this fact, this work focuses on proposing a system of technical guidance (STG) to the retail customer of construction materials that aims to assist stakeholders in related shops above $300 \mathrm{~m}^{2}$. With this, aims to show the importance of information on the dissemination of knowledge to customers, which mostly do not have the knowledge in current technical solutions for their needs. This lack of preparation justifies the creation of a STG for the retail customer of construction materials. This will be based on the creation of a platform that will help this audience towards a correct material specification. As a case study, the theme "waterproofing" as chosen, using an automatic diagnostic system. In this way, it is expected that there is a consequent improvement in the quality of sales and at the same time an increase in the average sale in construction retail shops.

Keywords: Construction. Professional Development. Skills. Guidance Systems. Communication at Point of Sale.
\end{abstract}

\footnotetext{
1 SANTOS, P. H. A.; SANTOS, E. T. Sistema de orientação técnica ao cliente do varejo de material de construção. In: ENCONTRO BRASILEIRO DE TECNOLOGIA DE INFORMAÇÃO E COMUNICAÇÃO NA CONSTRUÇÃO, 7., 2015, Recife. Anais... Porto Alegre: ANTAC, 2015.
} 


\section{7}

\section{TIC2015}

\section{INTRODUÇÃO}

O mercado da construção civil pode ser considerado como um dos principais alicerces para o crescimento de um país (IPEA, 2010). Até 2016, a população brasileira passará de 190 milhões para 206 milhões (IBGE, 2014), o que significa a necessidade de construção de 13,7 milhões de residências - só em 2010, o volume de investimentos em habitação ultrapassou R\$ 38 bilhões, alavancado pelo programa Minha Casa, Minha Vida. Segundo dados da ABRAMAT, as vendas de materiais de construção deverão crescer $77,7 \%$ entre 2011 e 2017. A importância do mercado da Construção Civil se observa pelos números expressivos da sua cadeia produtiva, que representa $8,8 \%$ do PIB brasileiro, sendo somente a venda de materiais de construção responsável por $4,1 \%$. Esses são conquistados com os seguintes dados (ANAMACO, 2013):

- 128 mil lojas de materiais de construção;

- 3 mil indústrias em 68 segmentos (hidráulica, elétrica, pintura, etc);

- 6 milhões de profissionais;

- 440.000 vendedores.

Aliado a estes números, segundo o IPEA, há um déficit de 7,9 milhões de moradias no País, o que corresponde ao total de $14,9 \%$ dos domicílios. De acordo com a ONU, 30\% da população brasileira vive em condições precárias.

Quem trabalha com o varejo, em lojas, seja de material de construção ou não, sabe das dificuldades de se ter um vendedor adequadamente treinado para atender o cliente. Além das técnicas de venda, é preciso saber do produto e ter segurança sobre o que se está vendendo. Na construção civil, é preciso evoluir constantemente a qualidade do atendimento e do pós-venda nas mais de 128 mil lojas brasileiras de materiais para construção. $O$ consumidor, na maioria das vezes, não conhece o produto, nem suas características, suas finalidades, suas aplicações, suas vantagens competitivas, etc. Normalmente, o cliente chega até a loja com um problema técnico e o vendedor é quem o auxilia na solução do problema. Nestas circunstâncias o consumidor, normalmente por desconhecimento, é obrigado a se colocar a mercê do vendedor, que deve atuar como um consultor. Para se posicionar como consultor, o vendedor deve ter um conhecimento completo técnico abrangente dos produtos que a loja comercializa (de 4.000 a 60.000 itens) ou pelo menos os do seu setor. O profissional de vendas da loja necessita também dominar as técnicas de negociação. Assim sendo, é um profissional que demora muito a ser formado e necessita estar sempre em constante aprendizado. Numa loja de materiais de construção, o treinamento técnico do vendedor sempre é constante, devido aos lançamentos de produtos de fabricantes dos mais diversos segmentos. E como $89 \%$ das lojas possuem acesso à internet (ANAMACO, 2013) o Sistema de Orientação Técnica (SOT) ao cliente do varejo de material de construção é uma ferramenta acessível a este público, em um país de proporções continentais como o Brasil.

Uma orientação adequada faz com que o cliente volte à loja e compre mais. Além de não existir maneiras efetivas e acessíveis a todas as lojas para vender os produtos incluindo sua instalação, como já acontece em muitos países, muitas vezes o comprador sai do local sem saber muito bem o que fazer com a mercadoria.

Lojas com um Sistema de Orientação Técnica, que disponibilizam informações sobre o sistema construtivo, sobre os produtos, as marcas, a instalação, vendem mais e têm menos problemas com reclamações e trocas. A indústria fica mais satisfeita, o consumidor fica feliz e o lojista pode ter um desempenho muito melhor. Por isso existe um grande interesse também por parte da indústria em treinar o público pagante de material de construção. 


\section{DEFINIÇÕES}

A ideia de cadeia produtiva está ligada aos vários estágios pelos quais as matérias primas passam e vão sendo transformadas e montadas. Para realizar essa transformação e montagem de matérias-primas em bens e serviços que serão comercializados junto ao público, as empresas utilizam recursos físicos, financeiros e humanos. Tomando como exemplo um apartamento novo, que está à venda em um edifício residencial, deve-se ter mente que sua oferta tem por trás uma extensa cadeia produtiva e um complexo processo de produção. Esse imóvel foi edificado por uma construtora que, para tanto, contratou mão de obra e investiu seu capital para empreender o negócio. Além disso, a construtora adquiriu materiais de construção e serviços que foram transformados e montados na obra. Assim, a construção realizada por essa construtora adicionou valor aos materiais de construção e aos serviços, os quais são produzidos por outras empresas.

A indústria de materiais e equipamentos, por sua vez, representou $16,8 \%$ do PIB e $5,6 \%$ do emprego da cadeia produtiva da construção em 2012. Boa parte da demanda por esses produtos da indústria de materiais é comercializada por empresas atacadistas e varejistas de materiais de construção, que também pertencem à cadeia produtiva. $O$ comércio representou $8,9 \%$ do PIB e 7\% do emprego da cadeia produtiva da construção em 2012. Além das empresas industriais e comerciais, há uma vasta gama de prestadores de serviços (técnicos, financeiros, de incorporação, etc.) que, direta ou indiretamente, estão envolvidos na cadeia produtiva da construção - esse segmento representou $6,5 \%$ do PIB e $5 \%$ do emprego da cadeia da construção em 2012 (ABRAMAT, 2013).

\subsection{Problema}

As lojas de grande porte de materiais de construção, também denominadas de Home Centers, possuem um tipo de venda na qual o próprio cliente (na maioria das vezes), retira o produto da gôndola e sem nenhum tipo de confirmação da efetividade do produto na necessidade apresentada, levam-no ao caixa, efetuam o pagamento e eventualmente continuam com suas dúvidas até o momento da aplicação, que pode ter sucesso ou não. $O$ desperdício de tempo em uma necessidade de troca, e os custos infligidos a loja e aos clientes são um grave problema para o mercado do varejo de materiais de construção. A análise em questão será realizada sobre o item impermeabilização, que em uma grande maioria dos casos gera uma grande dúvida em relação a sua correta especificação.

\subsection{Objetivo geral}

Propiciar nova tecnologia de orientação ao consumidor de materiais de construção no ponto de venda, melhorando a assertividade de sua compra e diminuindo os volumes de troca e devoluções.

\subsection{Objetivos específicos}

- Desenvolvimento de uma interface de comunicação com usuário no ponto de venda;

- Desenvolvimento de um sistema automatizado de orientação ao consumidor baseado em diagnóstico;

- Implantação de um sistema piloto em grande loja de varejo de materiais de construção para teste e validação do sistema.

\subsection{Justificativa}

As perdas nas lojas de materiais de construção mostram-se um obstáculo para a melhoria 
da produtividade deste segmento, visto que são consideradas perdas no varejo toda e qualquer interferência negativa no resultado da empresa, gerando como consequência a redução do lucro.

Dentro de um Home Center de materiais de construção, as perdas são divididas em quatro áreas de análise:

- Perdas por roubo;

- Perdas por quebra;

- Perdas por controle incorreto de estoque e;

- Perdas por troca e devoluções.

A somatória destes tipos de perdas representam algo em torno de $2 \%$ do faturamento total de um Home Center, sendo este último índice (perdas por trocas e devoluções) representa isoladamente aproximadamente $20 \%$ do volume das perdas totais. De acordo com informações de uma das maiores redes de Home Center do Brasil (informação pessoal) ${ }^{2}$ a somatória das perdas gira em torno de $0,4 \%$ do faturamento total, representando desta forma uma perda direta de mais de $\mathrm{R} \$ 15.200 .000$ /ano para as perdas por trocas e devoluções para a rede em todo o Brasil. Isto levando-se em consideração um faturamento anual de uma rede de materiais de construção da ordem de $R \$ 3,8$ bilhões (REVISTA INFRA, 2014).

Cada vez mais os lojistas, proprietários de lojas de materiais de construção, têm dificuldade em contratar mão de obra especializada na área da Construção Civil, visto que não há cursos específicos para a área, mas sim adaptações de cursos de vendas generalistas, sejam de diversas áreas, como farmacêutica, de vestuário ou automobilística. $O$ vendedor que é contratado muitas vezes não tem informações básicas iniciais de como uma residência é construída e, desta forma, tem dificuldade em auxiliar de uma maneira mais efetiva seus clientes, orientando apenas sobre as soluções básicas, sem expandi-las. Desta forma, um SOT servirá também para fortalecer o nível de informações para os vendedores, gerando assim um incremento em toda a cadeia de conhecimento, que será fortalecida com a ideia junto aos clientes de que as lojas suplementarão suas necessidades em relação aos produtos procurados. De acordo com informações de um Home Center, $60 \%$ dos clientes que realizam trocas e devoluções informam o erro no entendimento por parte dos vendedores.

\subsection{Impermeabilização}

A impermeabilização é o conjunto de operações e técnicas construtivas (serviços), composto por uma ou mais camadas, que tem por finalidade proteger as construções contra a ação deletéria de fluidos, de vapores e da umidade (ABNT NBR 9575:2010).

Trauzzola (1998) comenta que no Brasil, a partir da década de 60, o volume de construções aumentou de forma significativa, tanto na área habitacional como nas áreas industrial e pública, como resultado do crescimento econômico do país. O somatório dos dados relativos à falta de controle de qualidade da obra, projetos inadequados, profissionais despreparados, qualidade inferior de materiais de construção, mão-de-obra não profissionalizada e cronogramas inexequíveis, culminaram com uma baixa qualidade de construção, ocasionando, até hoje, altos custos de manutenção provenientes dos problemas patológicos, agravados pelo envelhecimento natural da construção.

\footnotetext{
2 Informação fornecida por Gerente Geral de um Home Center, São Paulo, em 29 março de 2014.
} 
Os principais danos causados pela umidade são analisados a partir da NBR (Associação Brasileira de Normas Técnicas, 1998) que define impermeabilização como sendo a proteção das construções contra a passagem de fluidos. Às vezes, para melhor definir a especificação da impermeabilização, faz-se necessário conhecer o efeito da infiltração. A umidade, entre outros danos, prejudica a boa aparência das edificações podendo causar os seguintes problemas: goteiras e manchas, bolor ou mofo, ferrugem, eflorescências, deterioração, além de degradação das pinturas.

Escolher a melhor solução e o produto mais adequado dentre os mais de 100 produtos disponíveis em um Home Center que atendam a necessidade que o cliente desconhece a patologia é o grande desafio de um SOT para o varejo de materiais de construção no que tange o sistema de impermeabilização.

\section{SISTEMA DE ORIENTAÇÃO TÉCNICA}

Nos últimos anos, muitos estudos concentram-se nas melhores práticas que fazem lojas (físicas e virtuais) mais atraentes, interessantes e de confiança para os consumidores. $O$ uso de estratégias de comunicação personalizadas e eficientes, dirigidas aos consumidores específicos é um tema importante de análise, pois os consumidores de materiais de construção normalmente se deslocam as lojas em busca de soluções as suas necessidades, e no caso específico de sistemas de impermeabilização, o cliente em $70 \%$ dos casos encontra-se em uma situação de problemas de infiltrações, de acordo com o IBI (Instituto Brasileiro de Impermeabilização). Além disso, um crescente interesse dos lojistas é usado para agregar valor às experiências dos clientes, buscando um diferencial competitivo. Enquanto o uso de novas ferramentas tecnológicas em lojas on-line é frequentemente estudado em pesquisas acadêmicas, a aplicação de novas tecnologias no ponto de venda de materiais de construção é relativamente inexplorado e um promissor campo de estudo. Em particular, a utilização de conteúdos digitais e tecnologias, permitindo que os consumidores interajam com os produtos em novas formas tem sido pouco utilizado. Um exemplo de utilizações de comunicação são totens LCDs com conteúdos em vídeo com ênfase de treinamento diretamente nas gôndolas, conforme mostra a Figura 1, em Home Center no estado de São Paulo:

Figura 1 - Totem LCD com atributos de tintas. Loja Leroy Merlin Center Norte (2014)

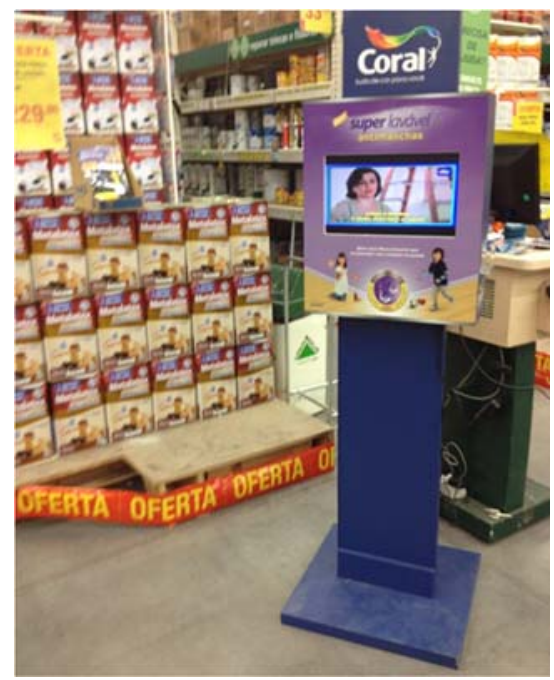

Fonte: Autor, 2014

Portanto, o desenvolvimento e a utilização de novas tecnologias, apoiando e influenciando os consumidores durante sua experiência de compra é uma área promissora de 
desenvolvimento acadêmico e profissional.

Adicionar conteúdo digital para essas ferramentas pode ser um meio poderoso para influenciar a experiência dos clientes. O objetivo é apoiar os consumidores, através de uma interface amigável, dando-lhes informações relacionadas com produtos, soluções técnicas, lançamentos e outros conteúdos de validade aos consumidores. As principais características são a interatividade e a multimodalidade, que suportam um sentimento eficiente, flexível e significativo de interação humano-tecnologia. Como consequência, essa interação poderosa é capaz de influenciar a satisfação do consumidor, bem como a lealdade aos varejistas de materiais de construção e comportamento de compra dos consumidores.

A introdução de tecnologias avançadas no contexto de varejo afeta a experiência do consumidor, em termos de percepção de produtos, a lealdade e a compra de intenção, promovendo um novo canal de comunicação eficiente entre empresas e consumidores, bem como envolvendo consumidores na criação de serviços altamente personalizados capazes de aumentar sua satisfação. No que tange sistemas de impermeabilização, o cliente tem uma grande quantidade de soluções, que muitas vezes mostram-se redundantes e confusas, dificultando a especificação do produto mais indicado para a necessidade do cliente.

\section{1 Árvore de Decisão (AD)}

O conceito de $A D$ será aplicado para analisar qual será o produto que efetivará a solução para o cliente, visto que o cliente tem a percepção do problema que está acontecendo em sua residência.

\subsection{MIT App Inventor 2}

Considerando que o SOT pretendido tem características de aplicação móvel, já que deve ser utilizado no ambiente físico da loja a partir do seu próprio dispositivo (celulares, tablets), mostra-se necessário a utilização de uma ferramenta de desenvolvimento para sua criação com esta característica. A ferramenta escolhida, portanto, será o MIT App Inventor 2, devido a sua característica de desenvolvimento de criação de aplicativos.

\section{METODOLOGIA DE PESQUISA E RESULTADOS}

\subsection{Pesquisa Construtiva}

O conceito de $A D$ será aplicado para analisar qual será o produto que efetivará a solução para o cliente, visto que o cliente tem a percepção do problema que está acontecendo em sua residência. O presente estudo adotou a Metodologia da Pesquisa Construtiva (Constructive Research). Ela é utilizada para definir e resolver os problemas, bem como para melhorar o desempenho, de um sistema existente, com a implicação global de gerar incremento no conhecimento existente.

A Figura 2 mostra os mecanismos da abordagem de pesquisa construtiva de trabalho. Ela começa com a identificação de problemas de relevância prática que têm potencial de investigação por meio de revisão de literatura teórica, e justificado com a experiência prática. 
Figura 2 - As características da abordagem de pesquisa construtiva.

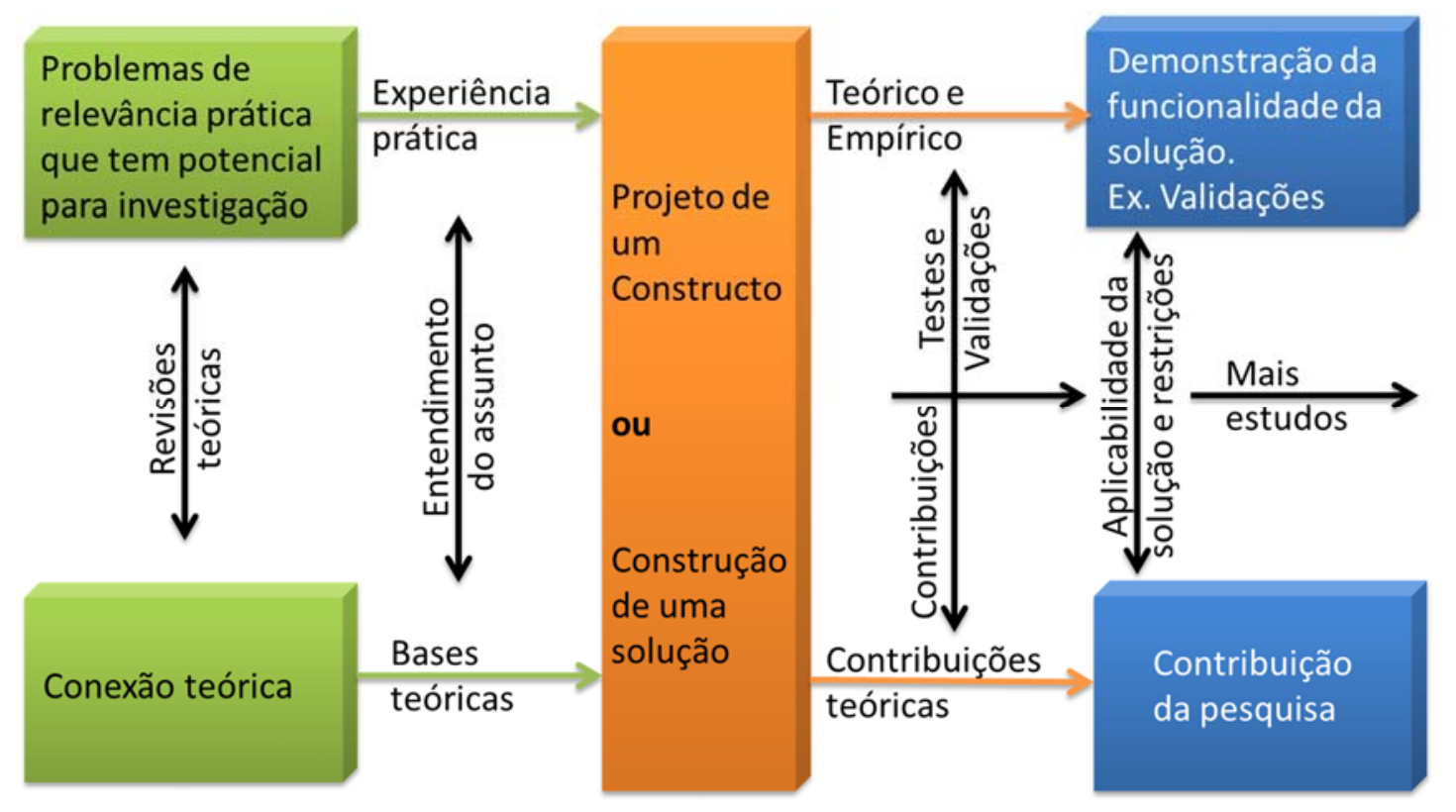

Fonte: adaptado de OYGOKE, 2011.

\subsection{Delimitação do SOT}

Para efeito de delimitação da análise de um SOT para sistemas de impermeabilização foi analisado o portfólio de soluções do fabricante Sika (www.sika.com.br) disponibilizados no Brasil, para os grupos de necessidades:

- Fundações e Subsolos;

- Túneis;

- Piscinas \& Reservatórios;

- Reparo e Proteção de Pisos Cerâmicos e Pedras;

- Áreas Úmidas;

- Impermeabilização de Pisos;

- Juntas de Concretagem;

- Fachadas;

- Umidade do Rodapé;

- Estruturantes (membranas líquidas);

- Coberturas;

- Tamponamentos de Infiltrações;

- Paredes de Gesso.

Esta quantidade de grupos de produtos e soluções que uma grande dificuldade no momento da especificação por parte dos vendedores e clientes de auto serviços. De acordo com o Coordenador de Projetos e Treinamento da Sika, Wadson Marques, a maneira de especificação utilizada hoje na empresa é fundamentada nas fichas técnicas dos produtos, que através de scripts informais alimentam as informações da equipe de atendimento ao consumidor para as chamadas recebidas de dúvidas e problemas existentes. Para as equipes de vendedores de Home Centers, são ministrados treinamentos presenciais, além da presença rotativa de promotores da marca Sika nos pontos de venda. A maneira pela 
qual o fabricante Sika apresenta suas soluções se dá através de fichas técnicas em formato PDF para download em seu site.

\subsection{SOT através de utilização de aplicativo}

Com uma conexão à Internet ou de dados móveis, será possível instalar o app através da Play Store. Através de uma fácil visualização, o cliente poderá clicar na área em que se encontra o problema e subsequentemente irá ser apresentada a solução desejada. A Figura 3 apresenta a tela inicial da interface gráfica.

Figura 3 - Exemplo de interface gráfica para análise de problemas.

\section{Clique no local onde encontra o seu problema de infiltração!}

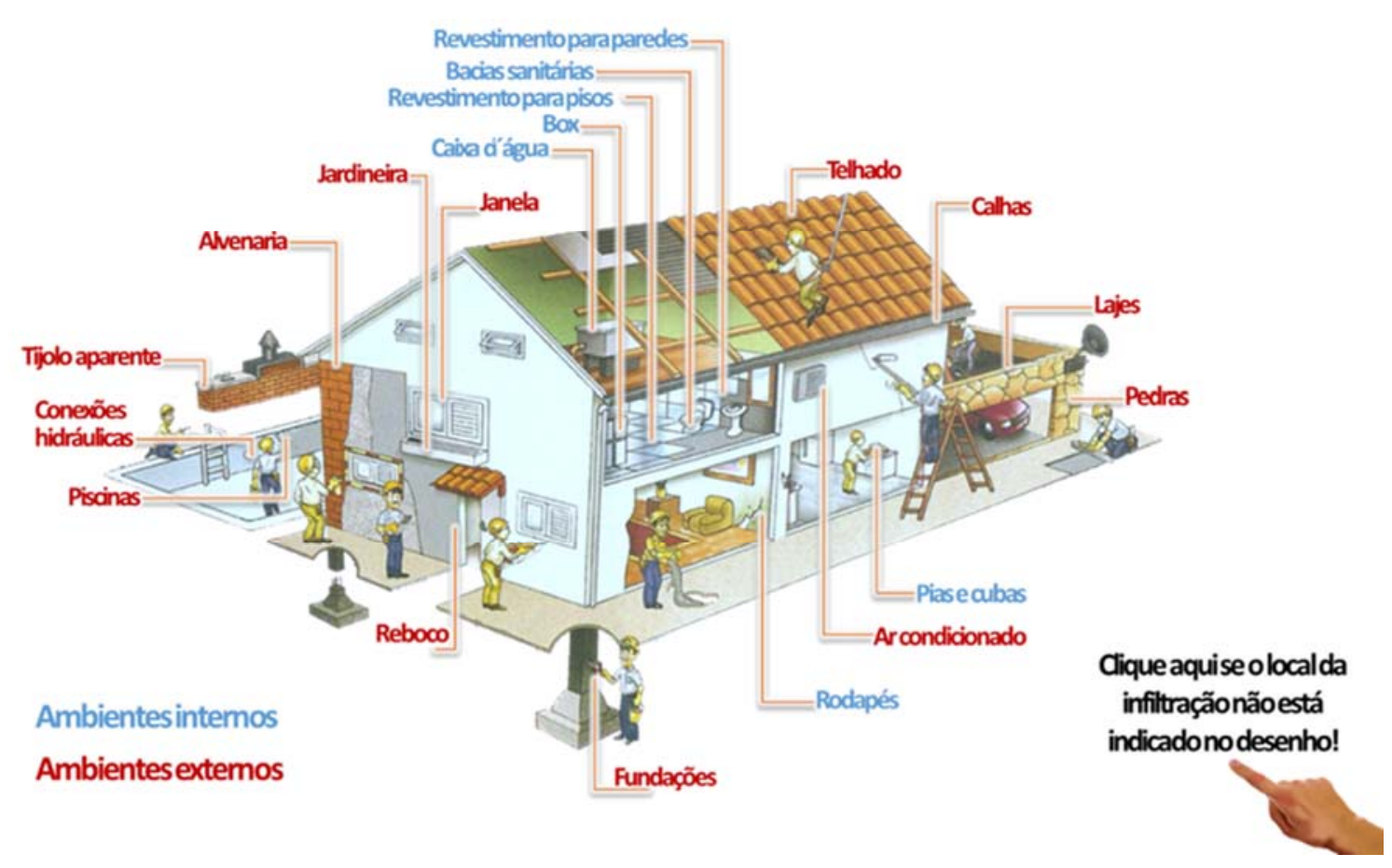

Fonte: Adaptado de SIKA, 2010.

Se nenhuma alternativa se apresentar para o cliente dentre as apresentadas, no canto inferior direito da tela informará uma opção na qual o cliente obterá o contato do fabricante com a opção direta para envio da dúvida a assistência técnica, que poderá enviar um técnico para fazer o laudo e gerar a respectiva solução.

Para a criação de um aplicativo que será usado diretamente no ponto de venda visando o auxílio da especificação no sistema de impermeabilização, na AD iremos utilizar como nodo raiz o problema principal, classificado como "infiltração". Como nodos filhos, utilizaremos a segmentação por áreas de familiaridade, sendo assim os ambientes "internos" e "externos", conforme apresenta a Figura 4. 
Figura 4 - Árvore de Diagnóstico para análise de problemas de infiltrações.

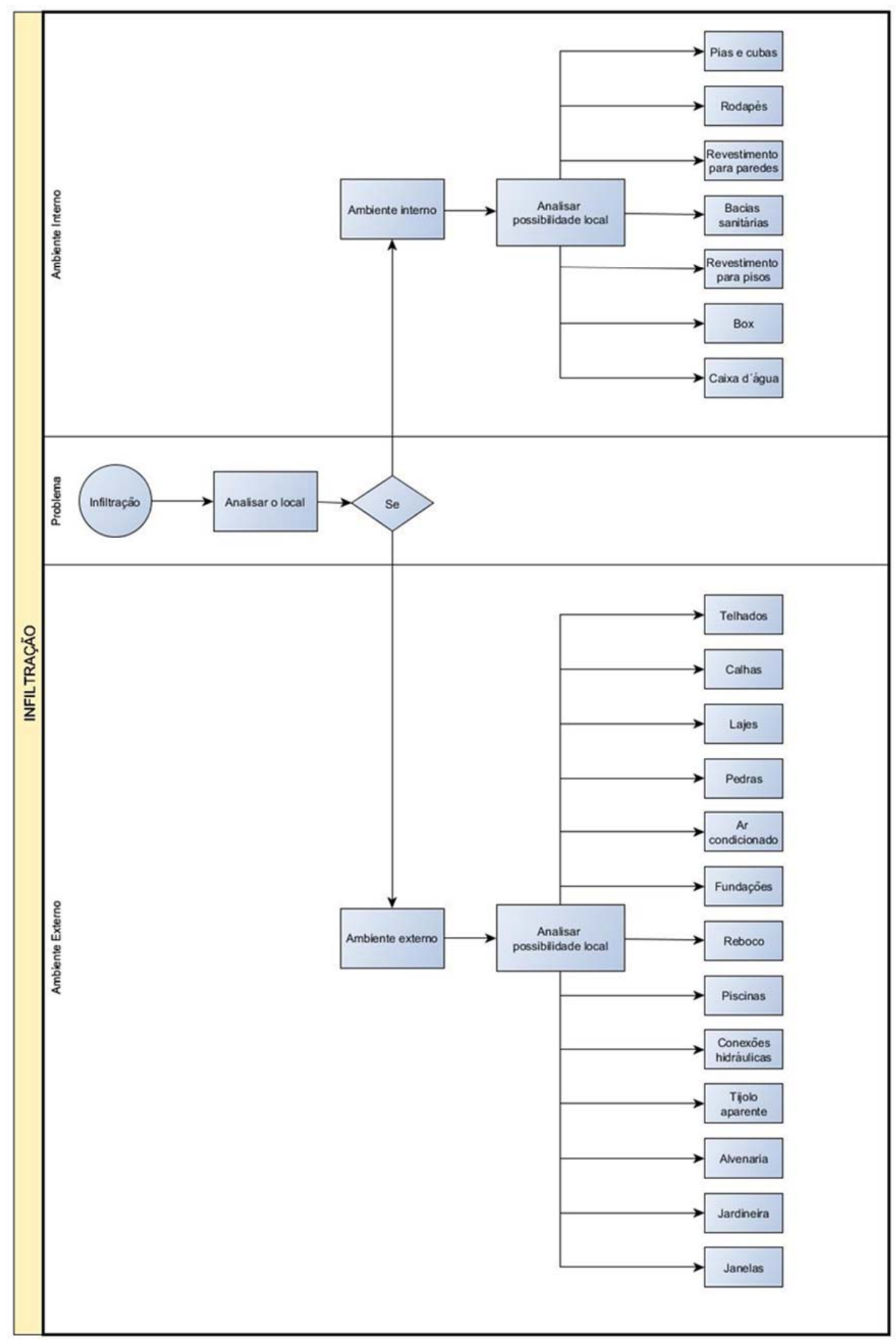




\section{1}

A partir de então, ela terá duas ramificações mistas, com as seguintes folhas:

- Ambientes internos:

- Pias e cubas;

- Rodapés;

- Revestimento para paredes;

- Bacias sanitárias;

- Revestimento para pisos;

- Box;

- Caixa d'agua.

- Ambientes externos:

- Lajes;

- Calhas;

- Telhados;

- Pedras;

- Ar condicionado;

- Fundações;

- Reboco;

- Piscinas;

- Conexões hidráulicas;

- Tijolo aparente;

- Alvenaria;

- Jardineira;

- Janelas.

Para efeito de apresentação do SOT será apresentada uma necessidade na qual o cliente apresenta problemas em sua laje. Para tanto, dentro da $A D$, será classificado como "ambiente externo", e o local, caracterizado como "lajes". Dentro deste nodo, teremos então uma ramificação binária, verificando se é uma construção nova ou se é uma reforma. Desta forma, teremos então dois nodos irmãos, de "lajes transitáveis" e "não transitáveis". Se forem lajes transitáveis, serão aquelas que irão receber uma pavimentação adequada ao trânsito de pedestres, mas não de veículos. Nessas regiões a impermeabilização rígida não é recomendada, pois estas lajes são susceptíveis de fissuras provenientes de oscilação térmica. Neste caso, recomenda-se mantas asfálticas ou elastoméricas, e através das informações pertencentes as fichas técnicas do fabricante Sika, poderemos indicar a solução mais adequada dentro das três possibilidades de produtos disponíveis para impermeabilização de lajes, a saber:

- Sika® Manta $3 \mathrm{Kg}$;

- Sika Manta PE 3mm Tipo I;

- Sika Manta PS 3mm Tipo II.

Se forem lajes não transitáveis, na qual somente pode se fazer uso esporádico de pedestres e não podem ser usados veículos, a impermeabilização rígida pode ser recomendada. Neste caso, poderemos indicar a solução mais adequada dentro de duas possibilidades de produtos disponíveis para impermeabilização de lajes do fabricante Sika:

- Sika® Manta PE Alum. 3mm Tipo I;

- Sika® Manta PS Alum. 3mm Tipo II. 


\section{和}

\section{CONCLUSÕES}

A principal motivação desta pesquisa encontra-se na tentativa de auxiliar os consumidores finais, que tem em sua experiência de compra grandes dificuldades em lojas do tipo Home Center, em virtude da dificuldade do acesso a informação. Desta forma, provendo informações diretamente no local da determinação da compra, iremos gerar vendas exatas, auxiliando com isso o interesse do público relacionado ao varejo de materiais de construção aliado a uma redução nas perdas referentes a trocas e devoluções. Além disso, é um mercado potencial, visto que as principais redes de varejo de materiais de construção do Brasil tem investido altos valores na readequação de seus processos. Um exemplo é a rede Leroy Merlin, que de acordo com seu presidente para o período de 2015 a 2019 terá investimentos da ordem de $\mathrm{R} \$ 2$ bilhões, buscando renovar suas lojas para torná-las mais próximas e mais interativas (REVISTA INFRA, 2014). Desta forma, um SOT se apresenta como uma ferramenta útil tanto do ponto de vista de redução de perdas, mas também do ponto de vista mercadológico, por conta da busca de diferenciação entre as redes de Home Center já aportadas no Brasil e as possíveis novas redes internacionais que tenham interesses no mercado Brasileiro.

\section{AGRADECIMENTOS}

O primeiro autor agradece ao apoio da Escola Politécnica da Universidade de São Paulo (USP). O segundo autor agradece ao apoio do CNPq - Conselho Nacional de Desenvolvimento Científico e Tecnológico e da Fundação de Amparo à Pesquisa do Estado de São Paulo (FAPESP).

\section{REFERÊNCIAS}

ANAMACO. <http://novo.anamaco.com.br>. Acesso em: 15 mar. 2014.

ABRAMAT. <www.abramat.org.br>. Acesso em: 15 mar. 2014.

ASSOCIAÇÃO BRASILEIRA DE NORMAS TÉCNICAS. NBR 6023: Informação e documentação Referências - Elaboração. Rio de Janeiro: ABNT, 2002.

NBR 9575: Impermeabilização - Seleção e projeto. Rio de Janeiro: ABNT, 2010.

CHIAVENATO, I. Gestão de Pessoas: O novo papel dos recursos humanos nas organizações. $6^{\mathrm{a}}$ edição. Rio de Janeiro: Campus, 1999.

CUNHA, A. G.; NEUMANN, W. Manual de impermeabilização e isolamento térmico: como projetar e executar. Rio de Janeiro: Barbieri, 1979. 227p.

EISEBHARDT, K. M.; GRAEBNER, M., Theory building from cases: opportunities and challenges, Academy of Management Journal, v. 50, n. 1, p. 25-32, 2007. Disponível em: $<$ http://tuta.aalto.fi/fi/opinnot/jatko_opinnot/jatko-opintokurssit/eisenhardtgraebner2007.pdf>. Acesso em: 19 mar. 2014.

KOWATSCH, T.; MAASS, W. In-store consumer behavior: How mobile recommendation agents influence usage intentions, products purchases, and store preferences, Computers in Human Behavior, v.26, n.4, p.697-704, 2010. Disponível em: <http://www.academia.edu/1914598/ Digital_contents_management_for_improving_consumers_experience>. Acesso em 29/03/2014.

MIT MIT App Inventor2. Disponível em: http://appinventor.mit.edu/explore/ai2/tutorials.html. Acesso em: 14 dez. 2014. 
MORAES, C. R. K. Impermeabilização em lajes de cobertura: levantamento dos principais fatores envolvidos na ocorrência de problemas na cidade de Porto Alegre. Porto Alegre, 2002, 91p. Dissertação de mestrado em Engenharia Civil. Programa de Pós-Graduação. PPGEC, 2002.

MUTTI, C. N. Treinamento de mão-de-obra na construção civil: um estudo de caso. 1995. Dissertação (Mestrado) - Universidade Federal de Santa Catarina. Florianópolis, 1995.

OYEGOKE, A. The constructive research approach in project management research. International Journal of Managing Projects in Business, v.4. n.4, p. 573-595, 2011.

PONTUAL, M. Evolução do treinamento empresarial. In: BOOG, G.G. Manual de treinamento e desenvolvimento ABTD. São Paulo: McGraw-Hill do Brasil, 1980.

REVISTA INFRA. Leroy Merlin investirá R\$ 2 bilhões até 2019. [Internet]. Disponível em: <http://www.talen.com.br/portal/Textos/?Acontece/15033/Leroy-Merlin-investir\%E1-R\$-2-bilh\%F5esat\%E9-20193925584->. Acesso em 09 dez. 2014

SIKA. <www.sika.com.br>. Acesso em: 06 nov. 2014.

TRAUZZOLA, Neuza Maria. A patologia nas edificações ocasionadas por infiltrações - estudo de caso. São Paulo, 1998, 81p. Dissertação de Mestrado em Engenharia de Materiais. Programa de Pós-Graduação, Instituto Mackenzie, 1998.

ULSAMER, F.. Las Humedades en la Construcción. Barcelona:Ediciones CEAC, 1989, 223p.

VERÇOZA, E. J. Impermeabilização na construção. Porto Alegre:Sagra, 1987, 151p.

$\mathrm{YU}, \mathrm{Y}$;; CAI, S. A new approach to customer targeting under conditions of information shortage. Marketing Intelligence \& Planning, v.25, n.4, p.343-359, 2007. 